\title{
Pemanfaatan Limbah Organik Berbasis Bio Cyclo Farming (Studi Kasus di Desa Telaga Murni)
}

\author{
Hiqmatus Sholichah $^{1}$ dan Annisa Nur Wahyuni ${ }^{2}$ \\ Faculty of Engineering, President University \\ Jl. Ki Hajar Dewantara, Jababeka Education Park, Cikarang, Jawa Barat 17550 \\ ${ }^{1}$ Sholichahhiqmatus@gmail.com, ${ }^{2}$ Annisan.nur.wahyuni@gmail.com
}

\begin{abstract}
Basically, United States Environmental Protection Agency (USEPA) stated that urban development depends on 3 pillars namely economic, social and environmental which can realize the balance of national development. Urban development is an important part of increasing the quality of the environment, living standards, capabilities and independence of the community. Urban development is focused on a city system that is strong, dynamic, and organized on the proper sustainability system. Urban areas have increasingly important roles with activities such as service centers, centers of production, distribution, and centers of innovation and socio-cultural progress. Youth as the nation's generation must play an active role in building urban balance, especially building community welfare in the form of real work, for example through the "Bricus-system" youth activity based on Bio Cyclo Farming which focuses on managing organic waste as a medium for cultivating earthworms (Lumbricus Rubellus) by reducing organic waste and carry out waste management processes to be reused in other sectors. Therefore, it is necessary to develop certain areas that can reduce the risk of largescale waste production, are environmentally sound and streak on the application of the concept of Bio Cyclo Farming, in this case, we form a business plan as the concept of implementing these activities. The purpose of this research is to achieve the role of the youth "Bricus-system" to improve environmental conditions which have a reduced function by utilizing organic waste as a medium for cultivation of worms that are expected to improve environmental and economic conditions. The research method used is a case study by observing areas that have problems developing urban equilibrium and making improvements to the area through "Bricussystem" youth activities based on Bio Cyclo Farming.
\end{abstract}

Keywords: The Role of Youth, Lumbricus Rubellus, Organic waste, Socio-Economic, Environmentally Friendly.

\begin{abstract}
Abstrak: Pada dasarnya United States Environmental Protection Agency (USEPA) menyatakan bahwa pembangunan perkotaan bergantung pada 3 pilar yaitu ekonomi, sosial dan lingkungan yang dapat mewujudkan keseimbangan pembangunan nasional. Pembangunan perkotaan menjadi bagian penting dalam meningkatnya kualitas lingkungan, taraf hidup, kemampuan dan kemandirian masyarakat. Pembangunan perkotaan dititik beratkan pada sistem kota yang kuat, dinamis, dan diselenggarakan pada tata kesinambungan yang tepat. Kawasan perkotaan semakin penting peranannya dengan kegiatan seperti pusat pelayanan, pusat produksi, distribusi, serta pusat inovasi dan kemajuan sosial budaya. Pemuda sebagai generasi bangsa harus berperan aktif dalam membangun keseimbangan perkotaan terlebih membangun kesejahteraan masyarakat dalam bentuk kerja nyata contohnya melalui kegiatan pemuda "Bricus-system" berbasis Bio Cyclo Farming yang terfokus pada pengelolaan sampah organik sebagai media budidaya cacing tanah (Lumbricus Rubellus) dengan usaha mereduksi limbah organik dan melakukan proses pengelolaan limbah untuk dimanfaatkan kembali pada sektor lainnya. Oleh karena itu diperlukan pengembangan kawasan tertentu yang dapat mengurangi risiko produksi limbah skala besar, berwawasan lingkungan dan beruntun pada penerapan konsep Bio Cyclo Farming, dalam hal ini penulis menyusun bussiness plan sebagai konsep implementasi kegiatan tersebut. Tujuan yang ingin dicapai dalam penelitian ini adalah melalui kegiatan peran pemuda "Bricus-system" untuk memperbaiki kondisi lingkungan yang mengalami penurunan daya fungsi dengan memanfaatkan limbah organik sebagai media budidaya cacing yang diharapkan dapat memperbaiki kondisi lingkungan dan ekonomi. Metode penelitian yang digunakan adalah studi kasus dengan melakukan observasi terhadap daerah yang mengalami masalah pembangunan keseimbangan perkotaan dan melakukan perbaikan daerah tersebut melalui kegiatan pemuda "Bricus-system" berbasis Bio Cyclo Farming.
\end{abstract}

Kata Kunci: Peran Pemuda, Lumbricus Rubellus, Limbah organik, Sosial- Ekonomi, Ramah Lingkungan.

\section{PENDAHULUAN}

Seperti yang kita ketahui menurut United States Environmental Protection Agency (USEPA), pembangunan perkotaan bergantung pada 3 pilar yaitu ekonomi, sosial, dan lingkungan yang dapat membantu mewujudkan keseimbangan pembangunan nasional. Pembangunan 
perkotaan dititik beratkan pada sistem kota yang kuat, dinamis, dan diselenggarakan pada tata kesinambungan yang tepat. Kawasan perkotaan semakin penting peranannya dengan kegiatan seperti pusat pelayanan, pusat produksi, distribusi, serta pusat inovasi dan sebagai pusat kemajuan sosial budaya. Seperti halnya kota Jababeka yang akan menjadi tempat penelitian peneliti. Kota Jababeka adalah sebuah kota berbasis industri mandiri terdapat rumah bagi lebih dari 1.650 lokal dan multinasional perusahaan dari lebih dari 30 negara, seperti Amerika Serikat, Jepang, Perancis, Inggris, Belanda, Australia, Korea, Singapura, Taiwan dan banyak lainnya. Kota Jababeka memiliki kawasan industri, perumahan dan komersial, jaringan transportasi umum, belanja, rekreasi dan tempat hiburan ${ }^{1}$. Dari analisa tersebut dapat terjadi kemungkinan masalah tata perkotaan karena faktor lingkungan maupun sosial yang belum seimbang, untuk itu dibutuhkan kesadaran diri dari individu maisng- masing untuk dapat memperbaiki masalah tata perkotaan melalui peran dari masyarakat maupun para pemuda.

Pemuda yang sadar akan potensi pesatnya industri di Cikarang, Jababeka memiliki peran aktif dalam mengkoordinasi sistem tata kota yang bersinergi dengan lingkungan, karena pemuda merupakan salah- satu bonus demografi yang sangat dibutuhkan oleh negara Indonesia untuk membantu mensukseskan pembangunan dibidang ekonomi, sosial dan lingkungan ${ }^{2}$. Disinilah peran pemuda sebagai generasi bangsa harus berperan aktif dalam membangun keseimbangan perkotaan terlebih membangun kesejahteraan masyarakat dalam bentuk kerja nyata contohnya melalui kegiatan pemuda "Bricus- system" berbasis Bio Cyclo Farming yang terfokus pada pengelolaan sampah organik sebagai media budidaya cacing tanah (Lumbricus Rubellus) dengan usaha mereduksi limbah organik dan melakukan proses pengelolaan limbah tersebut untuk dimanfaatkan kembali pada sektor lainnya.

Peran pemuda yang dimaksud adalah mahasiswa dari President University yang tergabung dalam suatu komunitas sosial dan memiliki tujuan untuk berkontribusi kepada masyarakat melalui kegiatan Bricus-system yang berbasis Bio Cyclo Farming. Sebab diperlukannya pengembangan kawasan tertentu yang dapat mengurangi risiko produksi limbah skala besar, berwawasan lingkungan dan beruntun pada penerapan konsep Bio Cyclo Farming, sehingga peneliti melakukan penelitian yang bertujuan untuk memperbaiki kondisi lingkungan yang mengalami penurunan daya fungsi dengan memanfaatkan limbah organik sebagai media budidaya cacing yang diharapkan dapat memperbaiki kondisi lingkungan dan ekonomi.

\section{METODE PENELITIAN}

Metode yang digunakan dalam penelitian ini adalah metode penelitian studi kasus. Pada proses tersebut terdapat beberapa teknik dalarn pengumpulan data, tetapi yang lebih dipakai dalam penelitian studi kasus adalah observasi, wawancara, dan analisis dokumentasi ${ }^{3}$. Disini peneliti melakukan observasi kasus yang terjadi disekitar daerah Cikarang Barat dengan bantuan LPPM (Lembaga Pengabdian dan Pemberdayaan Masyarakat) yang menyalurkan jasanya untuk memberikan data desa mana yang membutuhkan implementasi dari konsep Bricus-System berbasis Bio Cyclo Farming yang kemudian disosialisasikan kepada masyarakat dan melakukan wawancara pada salah satu peternak cacing Lumbricus Rubellus sebagai narasumber untuk menambahkan data yang telah diperoleh kemudian melakukan analisis, analisa data dilakukan sejak peneliti di lapangan, sewaktu pengumpulan data dan setelah semua data terkumpul atau setelah selesai dari lapangan, disini peneliti melakukan survei ke salah satu daerah yang ada di Cikarang Barat yaitu desa Telaga Murni, 
atas jasa kerjasama dengan LPPM (Lembaga Pengabdian dan Pemberdayaan Masyarakat) peneliti mendapatkan data yang lebih akurat dan dapat melakukan penyempurnaan dari data sebelumnya untuk dijadikan laporan penelitian.

\section{HASIL DAN PEMBAHASAN}

Sebelum kami melakukan implementasi dari kegiatan peran pemuda "BricusSystem”, kami mencari program kerja yang dapat dilakukan di desa Telaga Murni dan dapat mendukung aktifitas kawasan industri Jababeka yaitu dengan budidaya cacing tanah Lumbricus Rubellus. Kemudian kami bentuk sebagai business plan yang bertujuan untuk mengetahui kelayakan ekonominya. Berikut merupakan jalannya proses produksi dan rincian bussiness plan:

\section{PROSES PRODUKSI}

(Berdasarkan hasil wawancara dengan Bapak Hidayat)

\section{Bahan dan peralatan pembuatan media cacing:}

a. Tanah

b. Rak, bak, plastic

c. Kandang

d. Pelepah pisang, kotoran sapi, grajen kayu sengon

e. Limbah organik pasar

\section{Tahap pembuatan media cacing:}

1. Siapkan kotoran sapi 1 ember

2. Siapkan grajen kayu sengon 1 ember

3. Cacah pelepas pisang kecil-kecil

4. Campur hingga rata, dan masukkan ke dalam rak tempat hunian cacing

5. Cacing siap ditanam

Tahap pembuatan pakan cacing:

a. Blender halus bahan organic

b. Campurkan kotoran lembu secukupnya

c. Campurkan ampas tahu

d. Aduk secara rata dan tunggu 1 malam

e. Tuang pakan tersebut kesela-sela rak budidaya cacing

\section{RENCANA BISNIS}

Deskripsi Usaha

a. Bidang Usaha Dan Jenis Produk. Bidang usaha yang akan dilakukan dalam kegiatan Bricus-System yaitu usaha budidaya cacing yang telah dikembangkan untuk kepentingan komersial. Produk yang difokuskan untuk dipasarkan adalah cacing tanah jenis Lumbricus Rubellus yang dijual segar per kilogram beratnya. Selain itu terdapat produk lain yang bisa dijual yaitu kascing yang bisa dijadikan pupuk organik bagi para petani.

b. Kegunaan Dan Keunggulan. Kegunaan dari usaha ini diharapkan dapat menyediakan cacing segar Lumbricus Rubellus dalam rangka memenuhi kebutuhan Industri farmasi dan kosmetik terutama yang berada di Jababeka seperti PT. Dexa, PT. Feron Pharmacentical. Selain itu dapat memenuhi kebutuhan pakan untuk peternak burung, peternak ikan dan peternak bebek.

c. Lokasi Usaha. Usaha ini akan berlokasi di desa Telaga Murni, Cikarang Barat, Jawa Barat.

d. Waktu. Memulai usaha ini adalah sejak usulan rencana bisnis ini disetujui oleh LPPM (Lembaga Pengabdian dan Pemberdayaan Masyarakat) Jababeka untuk diimplementasikan di desa Telaga Murni.

e. Dampak Usaha Terhadap Lingkungan Usaha yang akan didirikan diharapkan dapat meningkatkan taraf hidup baik pelaksana maupun orang lain yang berkerja di usaha ini. Dari sisi sosial, dapat mempekerjakan masyarakat disekitar tempat usaha sehingga dapat mengurangi jumlah pengangguran. Dari sisi lingkungan, dapat memperbaiki kesuburan tanah yang mengalami penurunan karena kandungan dari Kascing tersebut ${ }^{4}$, dari sisi ekonomi, dapat membuka peluang usaha baru bagi masyarakat ekonomi bawah. 


\section{f. Resiko Bisnis}

\section{Resiko Internal}

Resiko internal yang akan dihadapi sebagian besar adalah masalah teknis peternakan $^{5}$. Contohnya seperti masalah pemberian pakan cacing Lumbricus Rubellus, penjadwalan dan sebagainya. Resiko internal lain adalah adanya kesalah-pahaman tugas para pekerja.

Resiko Eksternal

- Terjadi serangan hama tikus

- Menurunnya daya beli masyarakat

- Munculnya pesaing dibidang usaha ini

- Tidak tercapainya target penjualan.

\section{Rencana Pemasaran}

a. Segmentasi Pasar

b. Berdasarkan wilayah distribusi dan kemampuan konsumen yang akan mnjadi segmen pemasaran produk cacing tanah adalah peternak, distributor pakan diwilayah Cikarang Barat, PT. Jababeka Infrastruktur, PT. Dexa Medica Jababeka dan PT. Feron Pharmacentical.

c. Berdasarkan pendapatan. Pendapatan menengah kebawah mengarah kepada peternak untuk dikonsumsi sendiri. Pendapatan menengah keatas mengarah kepada distributor maupun industri pupuk kosmetik, dan pakan ternak untuk diolah kembali.

d. Berdasarkan hobi. Segmentasi kami adalah orang yang suka memancing, serta hobi berternak.

e. Target Pasar. Setelah menentukan segmentasi pasar, maka yang akan menjadi target pasar adalah peternak, serta distributor diwilayah Cikarang. Sementara umumnya adalah serta pelaku usaha bidang obat dan kosmetik diwilayah Cikarang terutama kawasan industri Jababeka dan sekitarnya yang peternak belum mengenal betul dengan produk cacing sebagai pakan ternak.

\section{Strategi Pasar}

Strategi pasar dapat diaplikasikan khususnya pada empat hal yaitu pada produk itu sendiri, harga produk, promosi produk kepada pasar, dan distribusi produk untuk dapat sampai pada konsumen ${ }^{6}$. Strategi pemasaran penting untuk direncanakan dan dipertimbangkan agar kegiatan usaha yang dilakukan tidak kalah bersaing dengan usaha lain yang bergerak dalam bidang yang sama. Strategi pasar yang digunakan 4P yaitu product, price, promotion, dan place ${ }^{7}$.

\section{a. Product (Produk)}

Produk yang difokuskan untuk dipasarkan adalah cacing tanah jenis Lumbricus Rubellus yang dijual segar per kilogram beratnya. Strategi yang digunakan untuk produk adalah keseragaman ukuran cacing melalui pengaturan pemberian pakan dan kebersihan cacing yang dipasarkan. Produk cacing ini merupakan salah satu produk yang memiliki multifungsi, baik untuk kepentingan persediaan industri pakan ternak dan ikan nasional, memasok kebutuhan farmasi dan obat-obatan, mengubah limbah organik menjadi media tanam yang baik dalam mendukung usaha pertanian, serta menumbuhkan usaha ekonomi kerakyatan ${ }^{8}$. Untuk produk kascing dijual kepada konsumen dan diberikan gratis untuk petani disekitar usaha ini.

\section{b. Price}

Harga yang ditetapkan untuk cacing dihitung per kilogram $(\mathrm{kg})$, dimana dipasar untuk satu kilogram cacing tanah dijual dengan harga kisaran antara Rp. 50.00070.000, harga yang ditetapkan dalam usaha ini adalah Rp. 60.000 per $\mathrm{kg}$. Untuk konsumen yang menjadi pelanggan tetap tidak menutup kemungkinan untuk mendapatkan potongan harga dan untuk pemesan berskala besar juga akan mendapatkan potongan harga. 


\section{c. Promotion (promosi)}

Usaha ini merupakan usaha baru dalam budidaya cacing Lumbricus Rubellus sehingga publikasi kepada konsumen sangat penting untuk dilakukan agar para konsumen dapat mengetahui adanya perusahaan disekitar mereka yang memproduksi cacing tanah. Untuk awal kami melakukan promosi dari mulut ke mulut dengan memanfaatkan hubungan baik dengan warga sekitar lokasi yang pada umumnya merupakan petani, peternak ikan, belut dan ayam di wilayah Cikarang Barat dan menjalin kerjasama dengan industri farmasi yang berada di kawasan Jababeka seperti PT. Dexa Medika, PT. Feron Pharmacentical, dan PT. Jababeka Infrastruktur. Untuk kedepannya kami melalukan promosi melalui media sosial seperti facebook, dan melalui pembuatan web atau blog agar lebih dikenal di wilayah Cikarang Barat dan sekitarnya.

\section{d. Place (lokasi)}

Pemilihan lokasi produksi merupakan salah satu alasan untuk menunjang distribusi produk kepada konsumen. Terjangkaunya lokasi oleh sarana transportasi akan memudahkan penyaluran produk kepada konsumen'. Sistem distribusi yang diterapkan untuk usaha ini adalah pengantaran langsung kepada konsumen dengan maksud memudahkan dan memanjakan konsumen agar tertarik untuk memesan produk. Tentu saja dengan memperhatikan lokasi konsumen dan skala pemesanan, untuk wilayah sekitar produksi tidak dikenakan tarif transportasi, sedangkan untuk luar wilayah produksi akan dikenakan biaya transportasi sesuai dengan lokasi konsumen, semakin jauh konsumen maka semakin besar pula tarif yang akan dikenakan.

\section{Rencana Manajemen}

a. Bentuk Usaha

Usaha ini berbentuk persekutuan karena dilihat dari jumlah pengelola yang menjalankan usaha peternakan cacing Lumbricus Rubellus.

b. Jumlah Tenaga Kerja

$\begin{array}{ll}\text { Manajer } & : 1 \text { orang } \\ \text { Bagian peternakan } & : 1 \text { orang } \\ \text { Bagian penjualan } & : 1 \text { orang } \\ \text { Bagian akuntansi } & : 1 \text { orang } \\ \text { Karyawan } & : 3 \text { orang }\end{array}$

c. Rencana Mitra

1. PT Jababeka Infrastruktur (Bagian Estate Management) yang mengelola sampah di Kawasan Industri Jababeka (KIJ) Cikarang dan mengoperasikan unit composting yang berlokasi di WWTP (Waste Water Treatment Plant).

2. LPPM (Lembaga Pengabdian dan Pemberdayaan Masyarakat) PT Jababeka Infrastruktur.

3. PT Dexa Medica.

4. PT. Feron Pharmaceutical.

Keterkaitan Kerjasama antara Pemangku Kepentingan ( Stakeholders)

Pemangku kepentingan :

a. Akademisi: President University

b. Masyarakat: Desa Telaga Murni

c. Lembaga Pengabdian dan Pemberdayaan Masyarakat

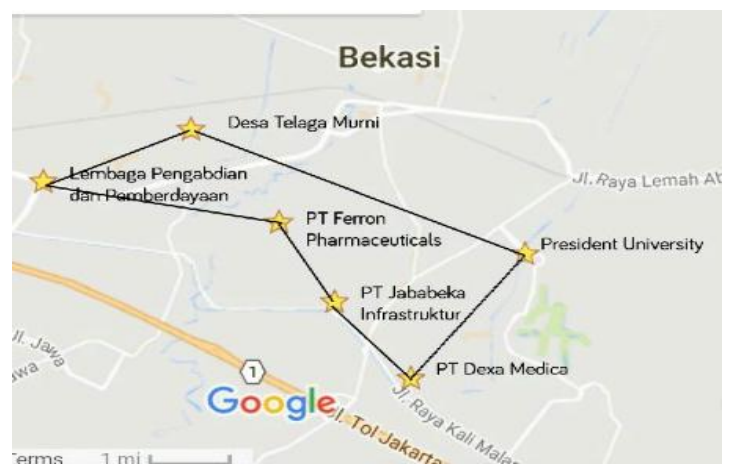

Gambar 1 Kolaborasi skematis geografis antara para stakeholder di gambarkan sebagai berikut (tanpa skala)

d. Pengelola Kota/Estate: PT Jababeka Infrastruktur (Bagian Estate Management) yang mengelola sampah di Kawasan Industri Jababeka (KIJ) Cikarang dan mengoperasikan unit 
composting yang berlokasi di WWTP (Waste Water Treatment Plant).

e. Industri: PT Dexa Medical dan PT. Feron Pharmaceutical

\section{Rencana Arus Keuangan}

\section{Asumsi :}

- Modal pinjam tanpa bunga

- Modal diperlukan setiap 4 bulan

- Penerimaan $80 \%$ pada rencana pendapatan yang berasal dari penjualan hasil

Sedangkan skema pola kerjasama antar stakeholders digambarkan sebagai berikut:

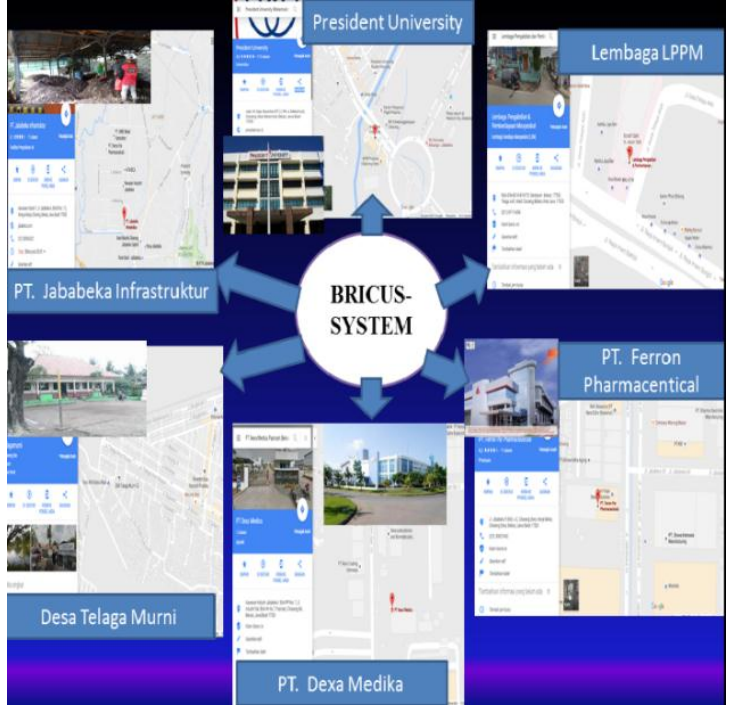

Gambar 2 Pola kerjasama antar stakeholders

Tabel 1 Arus Keuangan

\begin{tabular}{|c|c|c|c|c|c|c|}
\hline \multirow[t]{2}{*}{ Bahan } & \multirow[t]{2}{*}{ Quantity } & \multirow{2}{*}{$\begin{array}{l}\text { Harga } \\
\text { satuan }\end{array}$} & \multicolumn{4}{|c|}{ Perhitungan per bulan (x1000) } \\
\hline & & & 1 & 2 & 3 & 4 \\
\hline $\begin{array}{l}\text { 1. Sewa tanah seluas } 100 \mathrm{~m} 2 \\
\text { (per tahun) }\end{array}$ & $100 \mathrm{~m} 2$ & & 2.000 & & & \\
\hline $\begin{array}{l}\text { 2. Bangunan kandang bahan } \\
\text { bambu ( }(80 \mathrm{~m} 2)\end{array}$ & $80 \mathrm{~m} 2$ & & 2.000 & & & \\
\hline $\begin{array}{l}\text { 3. Rak } 1.5 \mathrm{~m} \times 1,8 \mathrm{~m} 2 \text { tinggi } 50 \\
\mathrm{~cm}\end{array}$ & 10 & 400.000 & 4.000 & & & \\
\hline 4. Plastic kasting per kg & $3000 \mathrm{~kg}$ & 1500 & 4.500 & & & \\
\hline 5. Bahan media cacing & 6 ton & 300.000 & 1.800 & & & \\
\hline 6. Plastic & $200 \mathrm{~m}$ & 6000 & 1.200 & & & \\
\hline 7. Pelepah pisang dicincang & 5 karang & 200.000 & 1000 & & & \\
\hline 8. Benih Cacing & $40 \mathrm{~kg}$ & 50.000 & 2.000 & & & \\
\hline 9. Pakan limbah sayur & $5000 \mathrm{~kg}$ & 500 & 2.500 & & & \\
\hline 10. Tenaga lierja & 3 arang & 800.000 & 2.400 & 2.400 & 2.400 & 2.400 \\
\hline 1. Transportasi & 1 & 200.000 hari & 1.200 & & & 4.000 \\
\hline Total & & & 24.700 & 2.400 & 2.400 & 6.400 \\
\hline $\begin{array}{l}\text { Sashrin } \\
\text { Produksi cacing }\end{array}$ & $600 \mathrm{~kg}$ & 60.000 & & & & $\begin{array}{l}36.000 \times 80 \%= \\
28.800\end{array}$ \\
\hline Produksi kascing & 2 ton & 15.000 & & & & $\begin{array}{l}30.000 \times 80 \%= \\
24.000\end{array}$ \\
\hline Total & & & & & & 52.800 \\
\hline Surplus & & & -24.700 & $\overline{27.700}$ & $-\overline{35.900}$ & $\begin{array}{l}16.900 \\
(47 \%)\end{array}$ \\
\hline
\end{tabular}

Dari analisis arus kas di atas diperoleh nilai surplus sebesar $47 \quad \% \quad$ (Rp 16.9000.000) dari total biaya yang diperlukan selama 4 bulan (Rp
35.900.000.). Dengan demikian usaha ini diproksikan layak untuk dapat dilaksanakan. 


\section{KESIMPULAN}

Dari penjelasan tersebut, dapat ditarik beberapa kesimpulan sebagai berikut:

1. Dari analisis business plan kegiatan "Bricus-System" layak untuk diterapkan di Desa Telaga Murni karena berpotensi mendapat dukungan dalam hal pemasaran cacing Lumbricus Rubellus dari industri farmasi skala besar (PT. Dexa Medica, PT. Feron Pharmaceutical), peternak burung maupun ikan, dan tempat pemancingan, serta dukungan kerjasama dengan PT Jababeka Infrastruktur yang mempunyai Lembaga Pengabdian dan Pemberdayaan Masyarakat (LPPM).

2. Jika bussiness plan ini diimplementasikan akan memberikan dampak yang positif kepada masyarakat dan lingkungan yaitu membantu memperdayakan masyarakat ekonomi lemah dan juga membantu penyuburan tanah melalui kascing.

3. Dapat memberikan kesempatan peran pemuda yang besar terhadap jalannya bisnis ini mulai dari penanggung jawab sampai dengan pelaksana sehingga akan memberikan dampak sosial yang positif.

\section{DAFTAR PUSTAKA}

Kota Jababeka. 2015. http://www.jababeka.com/id/ cikarang. Diakses pada tanggal 16 November 2016.

Naffs, Suzanne dan Ben White. 2012. Generasi Antara : Refleksi Tentang Studi Pemuda Indonesia. Jurnal Studi Pemuda. Vol.1 No. 2.

Margono,S. 2009. Metodologi Penelitian Pendidikan. Rineka Cipta, Jakarta.

Sudirja, R, 1999, Budidaya cacing tanah, Assosiasi kultur vermi Indonesia, Jatinangor.

Rahardi, F. dan R. Hartono, 2006. Agribisnis Peternakan. Cetakan kesepuluh. Penebar Swadaya, Jakarta.

Kumbhakar CS. 2002. Specification and estimation of production risk, risk preferences and technical efficiency. American Journal Agricultural Economic. 84(1): 8-22.
Jauch, lawrence R. 1993. Manajemen Strategis Dan Kebijakan Perusahaan, Erlangga, Jakarta.

Simantunjak, AK, D. Waluyo. 1982. Cacing dan Pemanfaatannya. PT. Penebar Swadaya Anggota IKAPI. Jakarta

Kotler, P. 2002. Manajemen Pemasaran. Edisi Kesepuluh, Jilid Dua.Terjemahan. Prenhallindo,Jakarta.

LPPM (Lembaga Pengabdian dan Pemberdayaan Masyarakat) Jababeka

Bapak Hidayat sebagai narasumber berpengalaman 5 tahun pada budidaya cacing Lumbricus Rubellus di Desa Telaga Murni, Cikarang Barat.

Rukmana, Ir. H. R. 2000. Budi Daya Cacing Tanah. Penerbit Kanisius, Yogyakarta.

Simantunjak, AK, D. Waluyo. 1982. Cacing dan Pemanfaatannya. PT. Penebar Swadaya Anggota IKAPI. Jakarta.

Kotler, P. 2002. Manajemen Pemasaran. Edisi Kesepuluh, Jilid Dua.Terjemahan. Prenhallindo,Jakarta.

Abdul Aziz A., M., 2015. Budidaya Cacing Tanah Unggul ala Adam Cacing. Jakarta: PT. Agro Media Pustaka. 